\title{
The use of the thermographic examination in non-specific low back pain in elderly: controlled study
}

\author{
Gabriela Santos Xavier', Danillo Barbosa², Mariane Pereira Batista³ ${ }^{3}$ Mônica Beatriz Ferreira4 ${ }^{4}$ Ivo Ilvan Kerppers², \\ Bruno Bonfim Foresti ${ }^{4}$
}

\begin{abstract}
Background: Chronic low back pain (CLBP) affects an important part of the population worldwide and contributes to increased spending on medicines and imaging tests. An alternative in the diagnosis of nonspecific CLBP is the thermography examination, since it has low cost, good sensitivity and specificity in inflammatory processes. Objectives: The present article aimed to evaluate non - specific CLBP in elderly patients using thermography (TermoScanTD200) and the instrument of inability of Oswestry. Methods: The study included 120 subjects with a mean age of \pm 78.8 years. Results: the results of the column disability assessment reported that $60 \%$ of the sample reported moderate disability and $3 \%$ of the sample reported disability. In the thermography examination, $40 \%$ of the sample presented alterations in the lumbar 5 (L5), 20\% showed changes in lumbar 3 (L3) and lumbar 4 (L4) and 10\% of the sample presented changes in lumbar 1 (L1) and lumbar 2 (L2). When comparing lumbar spine follow-up with type of inflammatory process, it was observed that $40 \%$ of the sample presented a prevalence of acute inflammatory process in the lumbar 5 (L5), and $30 \%$ of the sample presented a prevalence of sub-acute inflammatory process in lumbar 3 (L3) and $40 \%$ of the sample presented a prevalence of chronic inflammatory process in lumbar 5 (L5). Conclusion: In view of the above, it is suggested that the thermography examination is an important tool in the diagnosis of nonspecific low back pain in the elderly.
\end{abstract}

Keywords: Low Back Pain; Chronic Low Back Pain; Thermography; Physiotherapy.

\section{INTRODUCTION}

The infrared (IR) thermography examination has been widely applied in studies of accuracy, diagnosis and intervention, mainly in inflammatory processes. It has become a first-choice tool to aid in diagnosis, since the clinical evaluation is non-invasive, and presents good reliability and sensitivity, analyzing the tissue areas that eventually present thermal differences ${ }^{(1-3)}$. This examination captures a spectrum with wavelength of electromagnetic radiation, which cannot be visible to the human eye. The IR spectrum varies from $8 \mu \mathrm{m}$ to $15 \mu \mathrm{m}$. The thermal image taken by the examination is completely independent of the external light, but depends only on the passive radiation of any anatomical structure of the human body. Thus prolonged and repeated use can be done without any cellular damage, since it does not have a source emission of ionizing radiation ${ }^{(4)}$.

Lumbar pain affects a significant portion of the world's population, at different age levels, and may be persistent or recurrent. The symptoms can be physical and emotional, which can influence the levels of pain. It is important to report that chronic low back pain is characterized mainly by the duration of painful symptoms and physical incapacity greater than 3 continuous months ${ }^{(1)}$. It is estimated that in North America the total costs for the treatment of chronic low back pain exceed $\$ 600$ billion $^{(5,6)}$. Risk factors for low back pain (LBP) may vary according to the study population and may be influenced by age, type of work activity, psychological stress levels, and practice of sports activities. It is estimated that approximately $80 \%$ of the world population will present at least one incapacitating low back pain episode ${ }^{(7)}$. In view of the above, the objective of the present study was to analyze the incidence of chronic nonspecific LBP in elderly patients.

\section{MATERIALS AND METHODS}

\section{Type of study and research ethics}

This is a descriptive, analytical and controlled study. The study obeyed the ethical principles for research involving human beings, according to resolution 196/96 of the National Health Council, receiving the approval of the Research Ethics Committee of the University Center of Itajubá Fepi: CAAE: 43851415.4.0000.5094.

\footnotetext{
Corresponding Author: Danillo Barbosa. Rua Lamartine Silva Paiva, 960, Ap. 102 Condomínio Vilas do Atlântico - Bairro São Carlos, Pouso Alegre (MG) Tel: 005535984276895 . Email: danillo.barbosa@hotmail.com

2 Universidade Estadual do Centro-Oeste do Paraná - Unicentro - Departamento de Fisioterapia - Rua Salvatore Renna, 875 - Santa Cruz, Guarapuava - PR, CEP 85015-430, Brazil.
}

Full list of author information is available at the end of the article.

Financial support: None.

Submission date 27 October 2018; Acceptance date 10 December 2018; Publication date 31 December 2018 


\section{Sample Characteristics}

The study consisted of 120 male subjects, aged 78 78.8 years (Table 1 ).

\section{Inclusion and Exclusion Criteria}

To present age over 65 years, to have no history of spine surgery, to present pain symptoms for more than 6 months, not to be submitted is no specific drug or therapeutic treatment for spine, to be committed to participate in all phases of the study and sign and deliver the informed consent form. The exclusion criteria for the present study were: to be younger than 65 years of age, to have a history of spine surgery, to have pain symptoms of less than 6 months, to undergo any specific drug or therapeutic

\begin{tabular}{|c|c|}
\hline Color Pattern & Stage of the Inflammatory Process \\
\hline GREEN & Absence of Inflammatory Process \\
\hline YELLOW & Acute \\
\hline BROWN & Sub-Acute \\
\hline RED & Chronic \\
\hline
\end{tabular}

Figure 1. TermoScamTD200 ${ }^{\circledR}$ color scale. treatment for spine, not to commit in participating in all phases of the study and not signing and not delivering the informed consent form.

\section{Thermography Equipment and Image Acquisition Procedure}

In the present study, the TermoScamTD200 ${ }^{\circledR}$ was used, with a spatial resolution of $1024 \times 768$ pixels, a spectral range of $9.5 \mu \mathrm{m}$ to $16 \mu \mathrm{m}$ and a thermal sensitivity of $50 \mathrm{mK}$ at $30^{\circ} \mathrm{C}$. The Device is connected to a notebook by USB cable, and is managed by a specific software called TD200. The ThermoScamTD200 ${ }^{\circledR}$ thermography examination is used exclusively for spinal examinations, using a color scale to represent the tissue changes and to correlate with the stages of the inflammatory process (Figure 1).

The patients were carefully accommodated in the sitting position in a comfortable chair, with the torso slightly inclined forward (trunk flexion). The region to be examined was exposed and demarcated (lumbar 1 to lumbar 5), then the skin region was cleaned with $70 \%$ alcohol solution to decrease skin oiliness and not interfere with measurement. The thermography camera was placed on the lumbar vertebra 1 and the region was analyzed using the scan mode up to the lumbar vertebra 5 . The image was then projected onto the notebook and saved for later evaluation. The examination was performed 2 times in each patient (Figure 2).

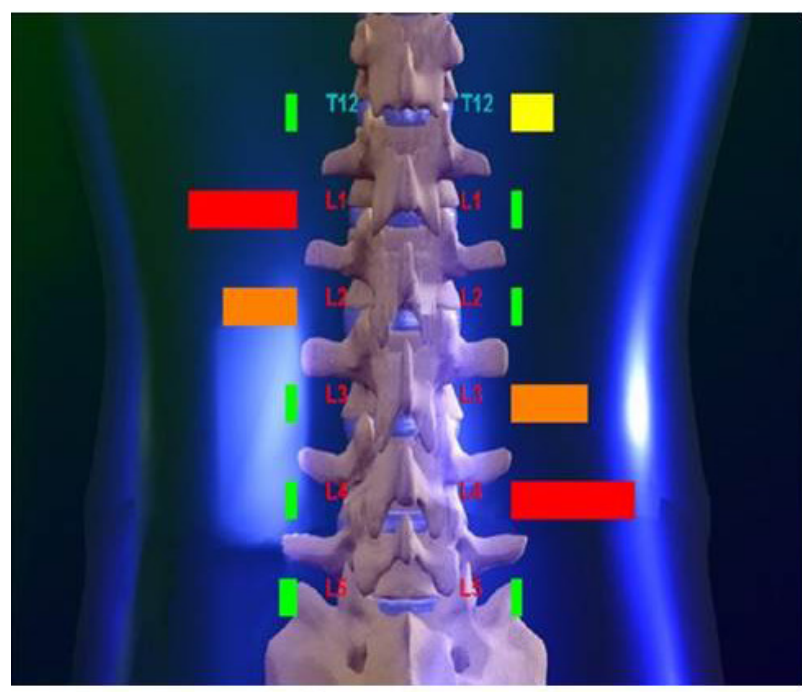

Figure $2 \mathrm{~A}$

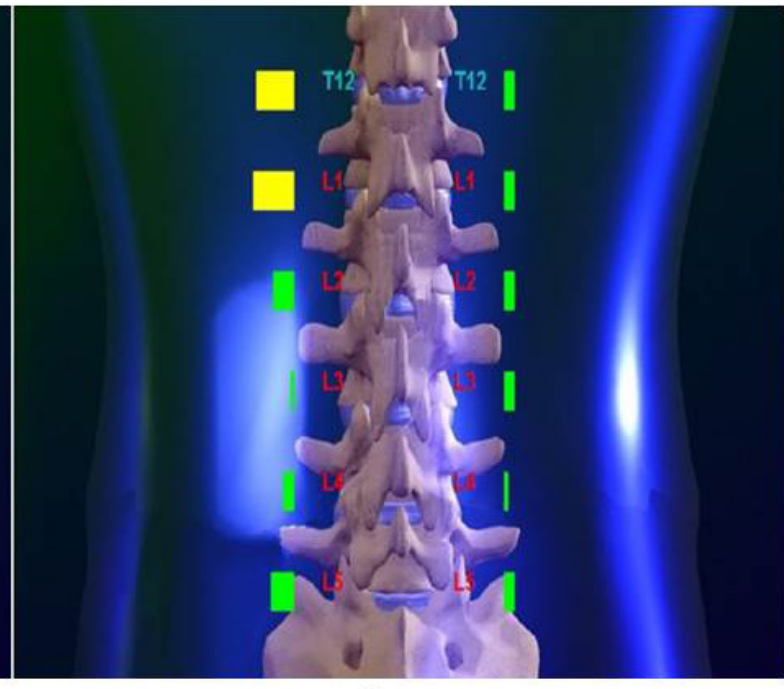

Figure 2 B

Figure 2. Example of the thermography examination (TermoScamTD200) ${ }^{\circledR}$. Note: Figure 2A shows that the lumbar 1 (L1), lumbar 2 (L2), lumbar 3 (L3), lumbar 4 (L4) and lumbar 5 (L5) bilateral segments are without increase in tissue temperature but the left lumbar segment 1 (L1) is an acute inflammatory process. Figure 2 B shows that right lumbar segments 1 (L1) and lumbar 2 (L2) are without temperature increase, while lumbar follow-up 3 (L3) has a sub-acute process, lumbar 4 (L4) has a chronic process and finally the lumbar 5 (L5) is without tissue change. Lumbar (L1) and lumbar (L2) follow-up are present with chronic and sub-chronic inflammation respectively, the other lumbar segments 3, 4 and 5 do not present tissue alteration.

Table 1. Sample characteristic.

\begin{tabular}{cccccc}
\hline Sample & Gender & Age & Weight (kg) & Altura (Mts) & Time of Pain (months) \\
\hline $\mathbf{N = 1 2 0}$ & Male & \pm 78.8 anos & \pm 89 & \pm 1.79 & \pm 18 \\
\hline
\end{tabular}

Note: Data on age; Weight, height and time of pain were expressed as mean. 


\section{Evaluation Instrument and Application Procedures}

\section{Oswestry Disability Index (ODI)}

It is a specific instrument used to evaluate lumbar spine function, including pain and physical activity variables ${ }^{(8-10)}$. This instrument contains 10 questions with 6 alternatives ranging from 0 to 5 . The first question assesses the intensity of pain and the other nine, the effect of pain on daily activities such as personal care (dressing and bathing), weight lifting, walking, sitting, standing, sleeping, in their sexual life, social and in locomotion. The total score is divided by the number of questions answered multiplied by the number 5 . The cutoff point for the Brazilian validation of ODI for low back pain is approximately 4.45 points $(63.2 \%$ sensitivity and $81.8 \%$ specificity), representing the minimum clinical sign that is important for this difference. Thus, the final evaluation follows this formula: ([score $\div$ (no questions answered $\times 5)] \times 100)^{(11)}$. The instrument was applied by an experienced evaluator in the context of orthopedic traumatic physical therapy, and it was blinded (Table 1).

\section{Data Analysis}

The data was entered into the microsoft excel ${ }^{\circledR}$ table, where it was calculated to the mean and standard deviation. The data were expressed in tables described by percentage.

\section{RESULTS}

Data analysis for the ODI showed that $60 \%$ of the sample reported moderate disability, and the disability-related index was reported by $3 \%$ of the sample $(n=3)$ (Table 2$)$.
The results of the thermography evaluation indicated the follow-up of the lumbar spine that presented the greatest repercussion of the inflammatory process; $40 \%$ of the sample presented lumbar changes $5,20 \%$ showed changes in lumbar 3 and 4 and $10 \%$ of the lumbar spine and showed changes in lumbar 1 and 2 (Table 3).

After the detailed evaluation of each thermography examination, it was observed that $* 40 \%$ of the sample presented a prevalence of acute inflammatory process in the lumbar 5 (L1), already \# 30\% of the sample presented a prevalence of sub-acute inflammatory process in lumbar 3 (L3) and $40 \%$ of the sample presented a prevalence of chronic inflammatory process in lumbar 5 (L5) (Table 4).

\section{DISCUSSION}

Infrared thermography exams analyze the thermal waves dissipated by the human body during the thermoregulation process, however, this thermoregulation can alter considering the health status of the patient as well as the local tissue situation $^{(11)}$. The technology of thermography exams began in the 1950s, but its technological development was slow, and it was only in the decade 2000 that there were significant advances and inclusion of this tool in clinical practice ${ }^{(12)}$. Recent studies ${ }^{(12)}$ have analyzed the improvements in thermography equipment, mainly in relation to the sensitivity of the sensors and cameras, improvement in the quality of resolution of the images, importance of the calibration of the equipment, according to the specific areas of the human body. The studies currently published do not provide

Table 2. Evaluation of the data for the analysis of the instrument of incapacity of Oswestry.

\begin{tabular}{ccc}
\hline Results (ODI) & $\mathbf{N}=\mathbf{1 2 0}$ & $\%$ \\
\hline Minimum Disability & $\mathrm{n}=17$ & 20 \\
Moderade Disability & ${ }^{\mathrm{n}} \mathrm{n}=60$ & 60 \\
Severe Disability & $\# \mathrm{n}=30$ & 10 \\
Crippled (Disability) & $\mathrm{n}=10$ & 7 \\
Invalid & $\mathrm{n}=3$ & 3 \\
Standard deviation & \pm 22.461 & 100
\end{tabular}

Note: Oswestry Disability Instrument: ODI; ${ }^{*} \mathrm{n}=60$ (dado mais significativo); $\# \mathrm{n}=30$ ( 20 dado mas significativo).

Table 3. Evaluation with thermography - lumbar spine.

\begin{tabular}{ccccc}
\hline Lumbar Spine & Lumbar $\mathbf{1}$ & Lumbar $\mathbf{2}$ & Lumbar $\mathbf{3}$ & Lumbar $\mathbf{4}$ \\
\hline $10 \%$ & $10 \%$ & $20 \%$ & $20 \%$ \\
\hline
\end{tabular}

Table 4 - Type of inflammatory process $x$ lumbar spine

\begin{tabular}{|c|c|c|c|c|c|}
\hline Inflammatory process & Lumbar 1 & Lumbar 2 & Lumbar 3 & Lumbar 4 & Lumbar 5 \\
\hline Acute & $10 \%$ & $20 \%$ & $20 \%$ & $10 \%$ & $* 40 \%$ \\
\hline Sub-acute & $15 \%$ & $20 \%$ & $\# 30 \%$ & $15 \%$ & $20 \%$ \\
\hline Chronic & $10 \%$ & $15 \%$ & $15 \%$ & $20 \%$ & $\$ 40 \%$ \\
\hline
\end{tabular}

Note: *40\% (dado com maior significância no estado acudo); \#30\% (dado com maior significância no estado sub-acudo); \$\$40\% (dado com maior significância no estado crônico). 
information when detailed when used in image evaluation software, and some studies do not provide data regarding the configuration characteristics of the equipment. In the present study, the patients were analyzed in an air-conditioned room, with an ambient temperature of $18^{\circ} \mathrm{G}$. All patients had their body temperatures evaluated, being considered as normal temperature values within $\pm 37.0^{\circ} \mathrm{C} \pm 37.5^{\circ} \mathrm{C}$. There are no current reference values for optimal spine temperature for the thermography examination, however, in order to have a parameter, the reference values of the knee region were used in this study, according to the studies performed ${ }^{(12)}$, pointed out that the ideal temperature of the knee region should be between $\pm 36^{\circ}$ to $\pm 38^{\circ} \mathrm{C}$.

\section{CONCLUSION}

In view of the above, it is suggested that the thermography examination can be used to aid the diagnosis of nonspecific low back pain in the elderly, since it does not present direct or indirect risks to the patient and the professional. With regard to low back pain in the elderly, a high prevalence of low back pain was observed in these subjects, portrayed by the thermography examination and the disability index. Facing the facts, it is essential to include specific intervention meditations for each subject.

\section{AUTHOR'S CONTRIBUTION}

GSX: correction of the research project, the Portuguese text and statistical data; DB: revised the final text and Portuguese version and responsible for translating text and graphics; MPB: responsible for the initial project, ethics committee submission, data collection and revision of the text in Portuguese; MBF: revised the ingles text; IIK: revised the ingles version and was the intellectual mentor; BBF: assistance in data collection, review of data in Portuguese and review of data in English.

\section{CONFLICTS OF INTEREST}

The author(s) declare that they have no competing interests.

\section{AUTHORS DETAILS}

${ }^{1}$ Programa Ciências da Reabilitação - Universidade Federal de Alfenas - Unifal - Campus Alfenas - Departamento de Fisioterapia - Adress: Rua Jovino
Fernandes de Sales, 2600 - Santa Clara, Alfenas - MG, CEP 37130-000, Brazil.

${ }^{3}$ Centro Universitário de Itajubá - Fepi - Departamento de Fisioterapia Traumato Ortopédica e Desportiva - Av. Dr. Antônio Braga Filho, 687 - Porto Velho, Itajubá - MG, Brazil. CEP 37501-002.

${ }^{4}$ Centro Universitário do Sul de Minas Gerais - Unis - Varginha, MG, Brazil.

\section{REFERENCES}

1. Lerkvaleekul B, Jaovisidha S, Sungkarat W, Chitrapazt N, Fuangfa P, Ruangchaijatuporn $\mathrm{T}$, et al. Comparisons between thermography and ultrasonography with physical examination for wrist joint assessment in juvenile idiopathic arthritis. Physiological Measurement. 2017; 38: 691-9.

2. Etehadtavakol M, Ng EY. Assessment of Foot Complications in Diabetic Patients Using Termography: A Review. In Application of Infrared to Biomedical Sciences. Springer Singapore, 2017, p.33-9.

3. Garcia K, Joanne Y, Kit-Lun Y, Mei-Chun C, Chi-Yung T, Sun-Pui N. Ameersing L. Postural Screening for Adolescente Idiopathic Scoliosis With Infrared Thermography. Scientific Reports. 2017; 7: 14431-6

4. Czaplik M, Hochhausen N, Dohmeier H, Barbosa PC, Rossaint R. Development of a "Thermal-Associated Pain Index" score Using InfraredThermography for Objective Pain Assessment. IEEE. 2017; 1:2-9.

5. Gaskin DJ, Richard P. The economic costs of pain in the United States. J Pain. 2012;13:715-24.

6. Hoy D, Brooks P, Blyth F, Buchbinder R. The epidemiology of low back pain. Best Pract Res Clin Rheumatol. 2010;24:769-81.

7. Gotfryd A, Filho ESV, Viola DC, Lenza M, Silva JA, Emi AS, et al. Análise epidemiológica, de hábitos de vida e de fatores psicossociais de pacientes com dorso lombalgia em unidade de pronto atendimento ortopédico. Einstein. 2015; 13: 243-248.

8. Falavigna A. Instruments of Clinical and Function Evaluation Spine Surgery. Coluna/Columna. 2011; 10:62-7.

9. Vigatto R, Alexandre NM, Correa FHR. Development of a Brazilian Portuguese version of the Oswestry Disability Index: cross-cultural adaptation, reliability, and validity. Spine. 2007; 32: 481-6.

10. Coelho RA, Siqueira FB, Ferreira PH, Ferreira ML. Responsiveness of the Brazilian-Portuguese version of the Oswestry Disability Index in subjects with low back pain. Eur Spine J. 2008;17:1101-6.

11. Diakides NA, Bronzino JD. eds. Medical Infrared Imaging. London - New York: Taylor \& Francis, 2008, p. 33-9.

12. Shterenshis M. Challenges to Global Implementation of Infrared Thermography Technology: Current Perspective. Central Asian Journal of Global Health. 2017; 6: 1-5. 